\title{
Aromatherapy Massage Affects Menopausal Symptoms in Korean Climacteric Women: A Pilot-Controlled Clinical Trial
}

\author{
Myung-Haeng Hur ${ }^{1}$, Yun Seok Yang $^{2}$ and Myeong Soo Lee ${ }^{3}$ \\ ${ }^{1}$ Department of Nursing, Eulji University, ${ }^{2}$ Department of Obstetrics \& Gynecology, School of Medicine, \\ Eulji University and ${ }^{3}$ Department of Medical Research, Korea Institute of Oriental Medicine, Daejeon, \\ South Korea
}

\begin{abstract}
This study investigated the effects of aromatherapy massage on menopausal symptoms in Korean climacteric women. Kupperman's menopausal index was used to compare an experimental group of 25 climacteric women with a wait-listed control group of 27 climacteric women. Aromatherapy was applied topically to subjects in the experimental group in the form of massage on the abdomen, back and arms using lavender, rose geranium, rose and jasmine in almond and primrose oils once a week for 8 weeks (eight times in total). The experimental group reported a significantly lower total menopausal index than wait-listed controls $(P<0.05)$. There were also significant intergroup differences in subcategories such as vasomotor, melancholia, arthralgia and myalgia (all $P<0.05$ ). These findings suggest that aromatherapy massage may be an effective treatment of menopausal symptoms such as hot flushes, depression and pain in climacteric women. However, it could not be verified whether the positive effects were from the aromatherapy, the massage or both. Further rigorous studies should be done with more objective measures.
\end{abstract}

Keywords: aromatherapy-climateric-massage-menopausal

\section{Introduction}

Techniques for improving the health of post-menopausal women currently focus on reducing risk factors such as coronary heart disease, deep vein thrombosis, breast cancer and gallbladder problems, with which hormone replacement therapy (HRT) may be associated (1). Because of the potential for adverse reactions to HRT, it has been proposed that the use of phytoestrogens, plant constituents with a phenolic structure similar to estrogen, may be useful for relieving climacteric symptoms rather than HRT (2). Meta-analysis of 29 studies has shown that phytoestrogens alleviate climacteric

For reprints and all correspondence: Myeong Soo Lee, $\mathrm{PhD}$, Department of Medical Research, Korea Institute of Oriental Medicine, 461-24 Jeonmin-dong, Yuseong-gu, Daejeon 305-811, South Korea. Tel: 82(0)42 868 9266; E-mail: drmslee@gmail.com; mslee@kiom.re.kr symptoms and improve lipid profiles in post-menopausal women (3).

Aromatherapy is the therapeutic use of essential oils from plants and phytoestrogens have been found in some of the essential oils used in aromatherapy (4-6). Many studies have found that aromatherapy improves psychological symptoms such as anxiety, depression and mood swings, and induces more relaxed states in young and middle-aged women $(4,7-10)$. Several aromatic oils have been recommended as phytoestrogens because they include components related to the sex hormones $(4,6,11-13)$. Some of these oils have similar structures and functions such as clary sage, fennel, cypress, angelica and coriander $(4,12)$. It has been proposed that geranium oil balances hormones and that rose oil strengthen uterus function $(4,6,11,12)$. Evening primrose is recommended as a base oil in aromatherapy for menopausal women (14). However, the therapeutic effects of aromatherapy on climacteric symptoms are not well supported by 
clinical studies. This study was conducted to investigate whether lavender, rose geranium, rose and jasmine oils, which are used frequently in the clinical field for improving various menopausal symptoms or are recommended as phytoestrogens, improve menopausal symptoms in climacteric women when applied with massage.

\section{Participants and Methods}

\section{Participants}

Sixty participants took part in the study. Participants were eligible to participate in the program if: (i) they were between 45 and 54 years old; (ii) they were able to understand the content of questionnaires and experimental schedules; (iii) their endometrial thickness was $<6 \mathrm{~mm}$; (iv) they were below Class II in the Papanicolaou smear test; (v) they had no history of dysplasia or cervical cancer; (vi) they agreed to the use of aromatherapy and (vii) they had no allergy to aromatherapy in accordance with a skin test, which was done during the recruitment stage. The participants were assigned to an aromatherapy group $(n=30)$ and a wait-listed age-matched control group $(n=30)$. Eight participants (five from the experimental group and three from the control group) dropped out without completing the experimental procedure. We finally analyzed 52 participants (aromatherapy group, $n=25$; age $49.4 \pm 2.6$ years, mean $\pm \mathrm{SD}$; and control group, $n=27$; age $50.3 \pm 2.8$ years, mean $\pm \mathrm{SD}$ ). The experimental protocol was approved by the Institutional Review Board (IRB) at the University Hospital. All subjects agreed to participate in the study and signed the informed consent form of the IRB. No adverse effects occurred during the experiment and the data of all participants were available for analysis.

\section{Menopausal Symptoms}

The outcome measures were menopausal symptoms, as obtained through Kupperman's 11-item menopausal index $(15-17)$, before and after 8 weeks of treatment. The Kupperman index is a numerical conversion index including 11 menopausal symptoms: hot flushes (vasomotor), paresthesia, insomnia, nervousness, melancholia, vertigo, weakness, arthralgia or myalgia, headache, palpitations, and formication. The items were rated on the following four-point scale: 'none' (0), 'mild' (1), 'moderate' (2), and 'severe' (3). To calculate the Kupperman index, the symptoms were weighted as follows: hot flushes $(4 \times)$, parasthesia $(2 \times)$, insomnia $(2 \times)$, nervousness $(2 \times)$ and all other symptoms $(1 \times)$. Therefore, the highest potential score was 51 . The score for hot flushes was based on the number of complaints per day: mild (more than five), moderate (5-10) and severe (more than 10).

\section{Interventions}

\section{Massage and oils}

Each subject in the experimental group received one 30-min aromatherapy treatment session a week for 8 weeks (eight sessions in total). The treatment was a massage with essential oils of lavender, rose geranium, rose and jasmine diluted in almond and evening primrose oil. No treatment was provided to subjects in the control group, who continued their usual daily routines. The control group was provided the aromatherapy massage therapy after the 8 weeks had expired; however, the data were not collected.

The aromatherapy massage was given to subjects in the experimental group by the same certified aromatherapist (participants did not know her personally) at the same time and on the same day each week. The treatment involved an abdominal, back and arm massage with essential oils of lavender, rose geranium, rose and jasmine in a 4:2:1:1 ratio, diluted almond $(90 \%)$ and evening primrose oil $(10 \%)$ at a final concentration of $3 \%$. The massage treatment room was isolated and equipped with beds warmed by heating pads. Participants were requested to lie on a bed and rest after the abdominal massage.

\section{Massage method}

The massage began with effleurage strokes in the shape of a flat diamond, working clockwise with a pressure of 4 on a scale of $0-10$, where 0 is no pressure and 10 is crushing pressure. The left hand was placed on the right hand and both hands were placed on the lower right abdomen. The stroke went to the ribs and then across the abdomen to the lower left abdomen. A cushion was placed under the subject's knees to keep the abdomen relaxed. This was followed by gentle kneading at the left and right of the waist, and then stroking across the abdomen. Finally, the effleurage flat diamond stroke began again. The massage on the back and arms was done in the same way. The strokes were slow, smooth and continuous.

\section{Statistical Analysis}

The results were analyzed using SPSS software. All outcomes were compared using the unpaired $t$-test for between-group comparisons and the paired $t$-test for comparisons between baseline and post-treatment for subjects in the experimental group.

\section{Results}

The groups did not differ significantly in age, age of menarche, age at first birth, height or weight (Table 1). 


\section{Subcategories of Menopausal Symptoms}

Across all categories of menopausal symptoms measured by the Kupperman index, the mean scores were lower in the aromatherapy group after 8 weeks of treatment, whereas most scores in the control group increased (Fig. 1). There were significant intergroup differences in the amount of hot flushes, melancholia and arthralgia and myalgia (all, $P<0.05$ ). There were also significant reductions in hot flushes, paresthesia and melancholia for the aromatherapy group compared with baseline

Table 1. Homogeneity test for demographic characteristics $(N=52)$

\begin{tabular}{lllll}
\hline Characteristics & $\begin{array}{l}\text { Aromatherapy } \\
(n=25)\end{array}$ & $\begin{array}{l}\text { Control } \\
(n=27)\end{array}$ & $t$ or U & $P$ \\
\hline Age (year) & $49.4 \pm 2.6$ & $50.3 \pm 2.8$ & 1.25 & 0.22 \\
Menache age (year) & $15.2 \pm 1.3$ & $15.2 \pm 1.7$ & $336.0^{*}$ & 0.98 \\
First birth age (year) & $27.9 \pm 2.0$ & $27.3 \pm 2.0$ & $277.5^{*}$ & 0.27 \\
Height (cm) & $157.5 \pm 4.7$ & $157.0 \pm 4.5$ & 0.39 & 0.70 \\
Weight (kg) & $56.0 \pm 6.4$ & $58.3 \pm 6.6$ & 1.26 & 0.21 \\
Body fat (\%) & $30.0 \pm 5.2$ & $31.5 \pm 4.8$ & 0.97 & 0.34 \\
$\begin{array}{l}\text { Endometrial } \\
\text { thickness (cm) }\end{array}$ & $0.53 \pm 0.41$ & $0.42 \pm 0.29$ & $223.0^{*}$ & 0.26 \\
\hline
\end{tabular}

Values are expressed as mean $\pm \mathrm{SD}$.

*Mann-Whitney U test. (all, $P<0.05)$, whereas the melancholia score $(P<0.05)$ increased significantly in the control group.

\section{Total Menopausal Index}

The mean baseline level of the menopausal index did not differ between the two groups ( $t=0.72, P=0.47$; Fig. 2). However, after 8 weeks of treatment, Kupperman index scores differed significantly between the aromatherapy group and the control group $(t=-2.08, P=0.043)$, with significant changes from baseline in the aromatherapy group $(t=2.83, P<0.01)$. The change in the menopausal index level was more significant in the aromatherapy group than in the control group $(t=3.00, P<0.005$, aromatherapy: $\quad-5.44 \pm 9.60, \quad$ mean $\pm \mathrm{SD}$; control: $1.59 \pm 7.25)$.

\section{Discussion}

In this study, subjects who received an aromatherapy massage once a week for 8 weeks showed a greater reduction in menopausal symptoms than those in the control group. More specifically, aromatherapy massage improved hot flushes, depression and pain in climacteric women.

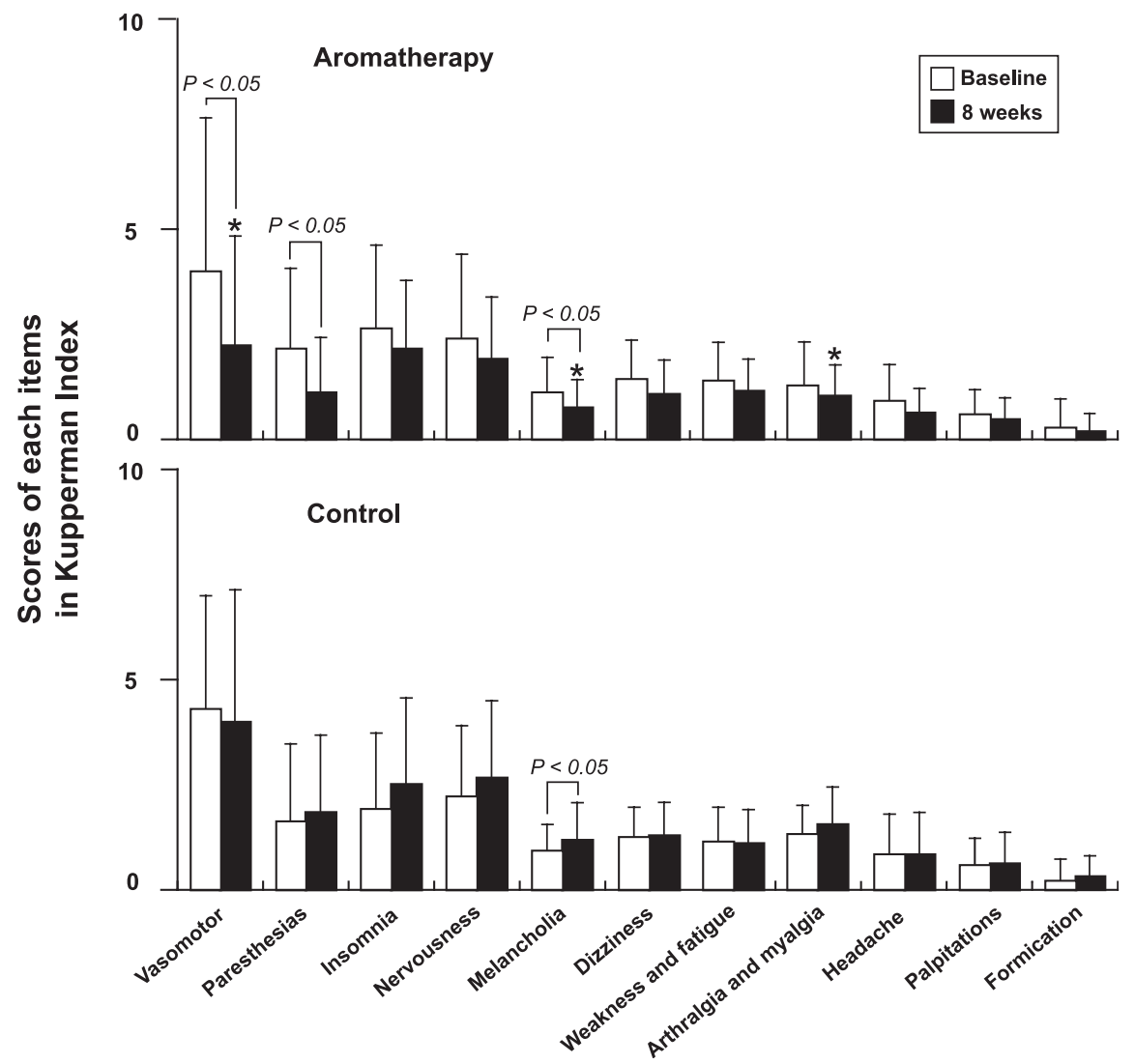

Figure 1. Scores for each item in the Kupperman index at baseline and after eight weeks in the aromatherapy group $(n=25)$ and the control group $(n=27) .{ }^{*} P<0.05$ compared with control group. 


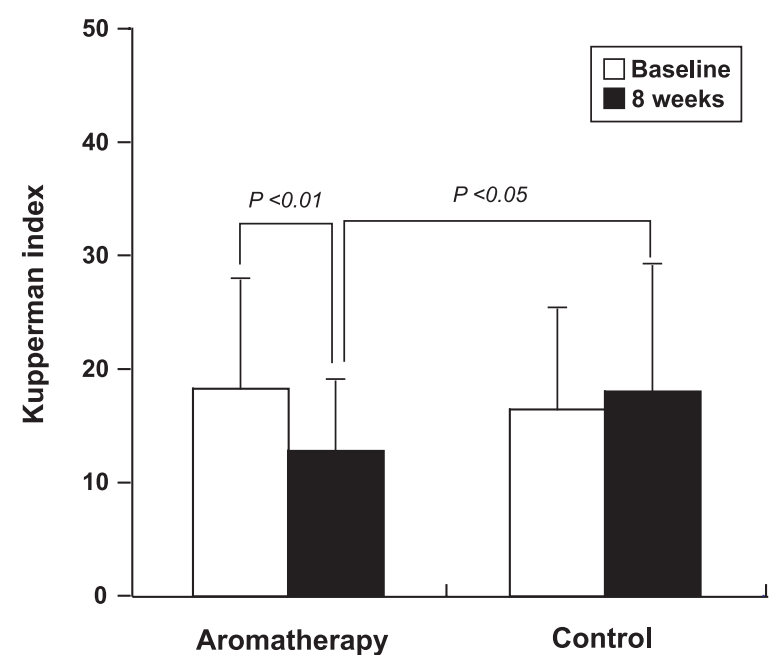

Figure 2. Mean Kupperman index score at baseline and after 8 weeks in the aromatherapy group $(n=25)$ and the control group $(n=27)$.

The results of the present study suggest that aromatherapy massage may improve menopausal symptoms of climacteric women. This is in accordance with previous uncontrolled trials, which reported improvement of menopausal symptoms through aromatherapy (13). Our study also supports the proposal that several aromatic essential oils have phytoestrogen effects on menopausal symptoms in climacteric women (8). Furthermore, aromatherapy massage improved hot flushes, depression and pain in the experimental group compared with the control group. These results are consistent with previous reports of the use of essential oils in treating each of these symptoms (8).

However, we acknowledge that our study has several limitations, such as non-randomized design and the lack of an equivalent-treatment control group to estimate the superior effectiveness of aromatherapy massage. Therefore, it is not clear whether the positive effects were due to the aromatherapy, the massage or both (e.g. identical results may have been achieved by using only massage, or by using aromatherapy and massage). Further randomized studies should be carried out that include more objective measures, such as hormonal changes associated with climacteric women, to explain the possible mechanism of reduction in menopausal symptoms.

\section{Acknowledgements}

This work was supported by the Korea Research Foundation Grant funded by the Korean Government (MOEHRD, Basic Research Promotion Fund) (KRF2004-002-E00179).

\section{References}

1. Pinkerton JV. Menopause and quality of life: the role of hormone therapy. Council on Hormone Education 2003;1:3-10.

2. Lucks BC, Sorensen J, Veal L. Vitexagnus-castus essential oil and menopausal balance: a self-care survey. Complement Ther Nurs Midwifery 2002;8:148-54.

3. Dodin S, Blanchet C, Marc I. Phytoestrogens in menopausal women: a review of recent findings. Med Sci (Paris) 2003:19:1030-7.

4. Buckle J. Clinical Aromatherapy. New York: Churchill Livingstone, 2003.

5. Dye J. Aromatherapy for Women \& Childbirth. Saffron Walden, UK: The CW Daniel company LTD, 1997.

6. Tisserand M. Aromatherapy for Woman, A Practical Guide to Essential Oils for Health and Beauty. Vermont, Canada: Healing Arts Press, 1996.

7. Diego MA, Jones NA, Field T, Hernandez-Reif M, Schanberg S, Kuhn C, et al. Aromatherapy positively affects mood, EEG patterns of alertness and math computations. Int J Neurosci 1998;96:217-24.

8. Field T, Diego M, Hernandez-Reif M, Cisneros W, Feijo L, Vera Y, et al. Lavender fragrance cleansing gel effects on relaxation. Int $J$ Neurosci 2005;115:207-22.

9. Kang JY, Kim KS. Effect of aromatherapy on anxiety and fatigue in students nurses experiencing their first clinical practice. $J$ Kor Acad Fund Nurs 2002;9:226-36.

10. Morris N, Birtwistle S, Toms M. Anxiety reduction by aromatherapy: anxiolytic effects of inhalation of geranium and rosemary. Int $J$ Aromather 1995;7:33-9.

11. Battaglia S. The Complete Guide to Aromatherapy. Queensland: The Perfect Portion, 1995.

12. Keville K, Green M. Aromatherapy: a Complete Guide to the Healing Art. Freedom, CA: The Crossing press, 1995.

13. Murakami S, Shirota T, Hayashi S, Ishizuka B. Aromatherapy for outpatients with menopausal symptoms in obstetrics and gynecology. J Altern Complement Med 2005;11:491-4.

14. Davis P. Aromatherapy an A-Z. London: Vermilion, 2005.

15. Alder E. The Blatt-Kupperman menopausal index: a critique. Maturitas 1998;29:19-24.

16. Blatt MH, Wiesbader H, Kupperman HS. Vitamin E and climacteric syndrome; failure of effective control as measured by menopausal index. AMA Arch Intern Med 1953;91:792-9.

17. Kaari C, Haidar MA, Junior JM, Nunes MG, Quadros LG, Kemp C, et al. Randomized clinical trial comparing conjugated equine estrogens and isoflavones in postmenopausal women: a pilot study. Maturitas 2006;53:49-58.

Received September 13, 2006; accepted December 28, 2006 


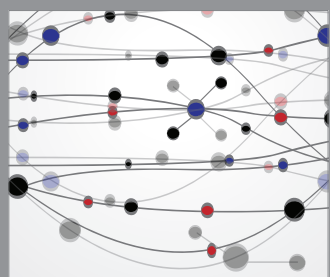

The Scientific World Journal


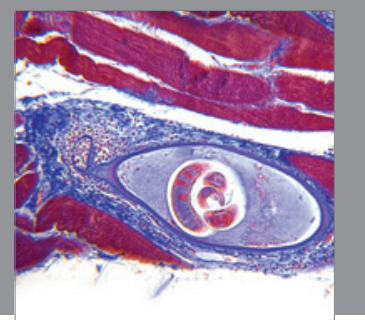

Gastroenterology

Research and Practice
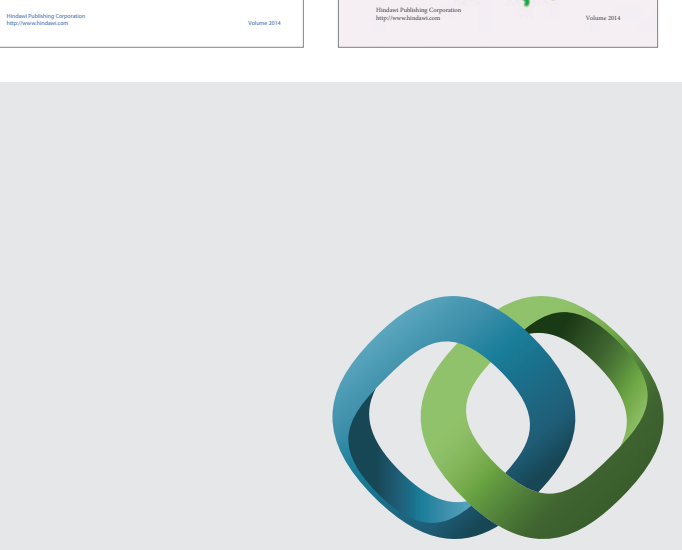

\section{Hindawi}

Submit your manuscripts at

http://www.hindawi.com
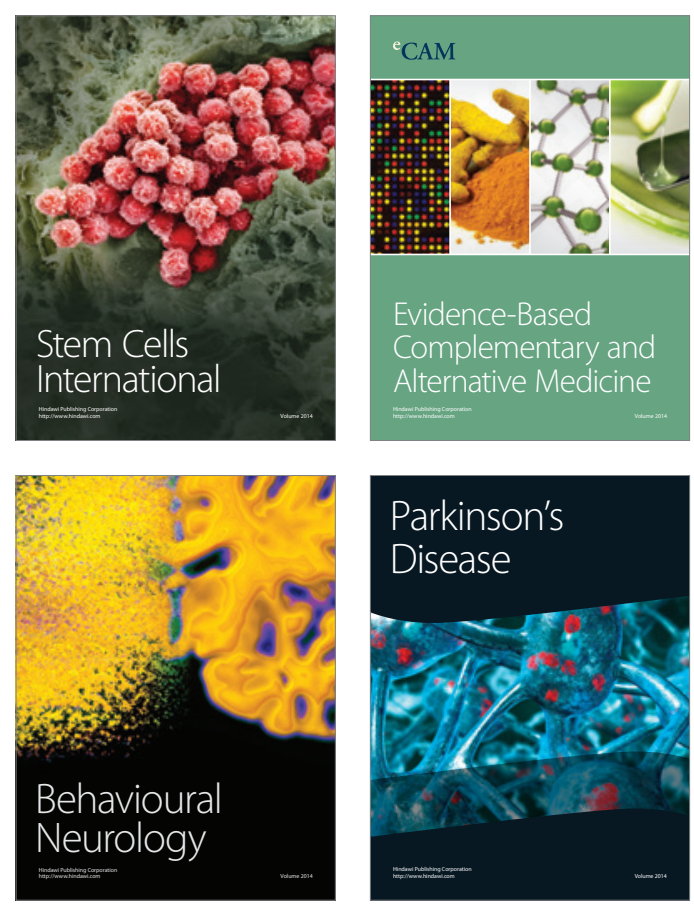

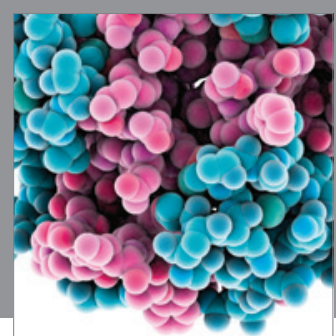

Journal of
Diabetes Research

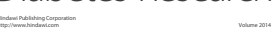

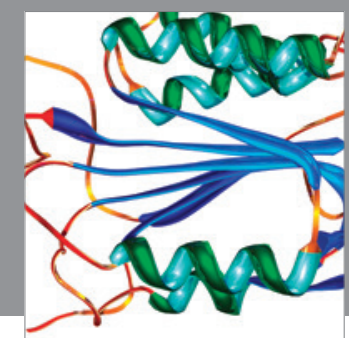

Disease Markers
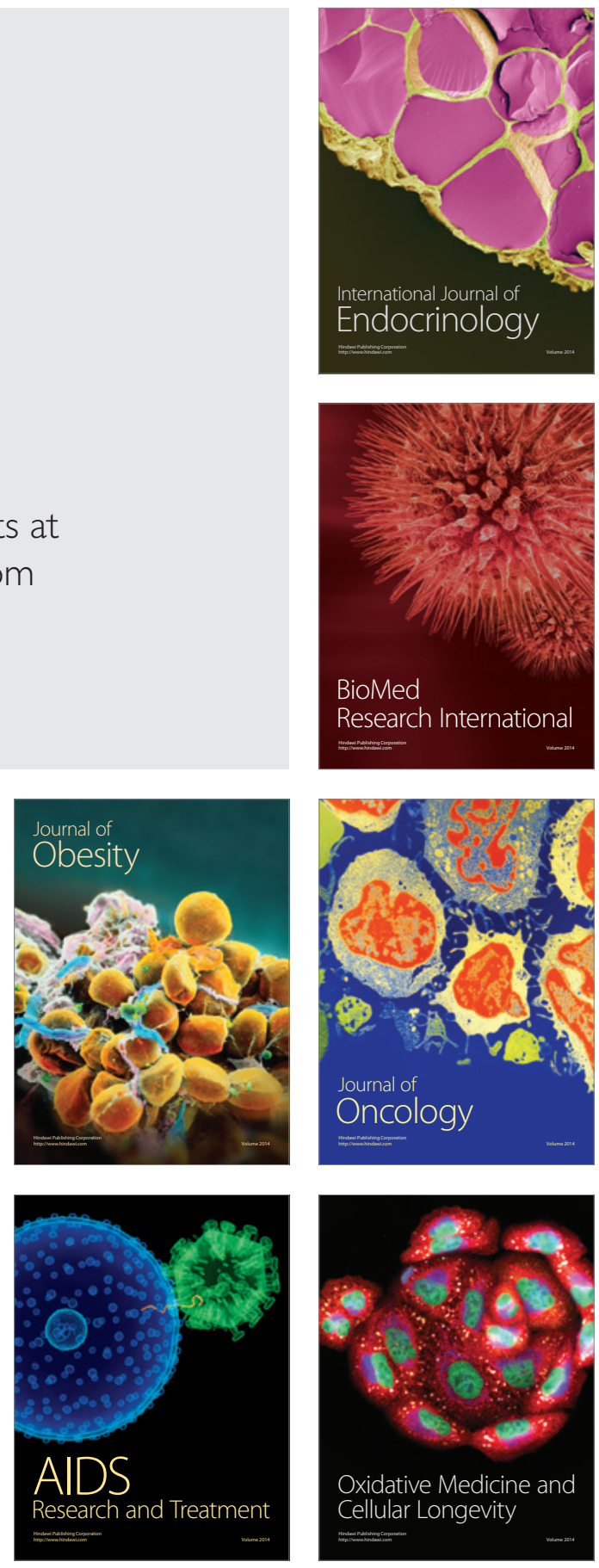